INTERNATIONAL JOURNAL OF MULTidisciplinARY RESEARCH AND ANALYSis

ISSN(print): 2643-9840, ISSN(online): 2643-9875

Volume 05 Issue 02 February 2022

DOI: 10.47191/ijmra/v5-i2-24, Impact Factor: 6.072

Page No. 399-409

\title{
Perception of Climate Risks and Issues of Adoption of Resilient Technologies by Farmers in Togo
}

\section{KAO Papa}

PhD student in Agricultural economics of university of Lomé (ESA/UL)

SUMMARY: In this paper, we develop a theoretical model to simultaneously describe the adoption of improved seed technology and the climate risk perception capacity of farmers facing production risks and incomplete information about the new technology. The adoption condition is derived from the assumptions of upstream climate risk perception and downstream farmer risk aversion, and assuming that uncertainty can arise from two sources: the randomness of climatic conditions and the uncertainty of future returns associated with the use of the new technology. We estimate a reduced form of this model through the Heckman selection probit using a sample of 545 plots distributed in the five regions of Togo. The estimation procedure is developed in two steps. In the first step, we estimate the first four moments of the benefit distribution and in the second step, we incorporate these estimated moments into the model of technology adoption and climate risk perception. We find that risk plays a central role in farmers' decisions, first through the direct effect of its perception and second through sampling moments of the yield distribution in the adoption model.

KEY WORDS: Risk, perception, technological adoption.

\section{INTRODUCTION}

The negative effects of climate change on agricultural production in constituted geographic areas are documented and are of concern beyond the scientific community, to policy makers and even to populations increasingly exposed to climate hazards (Lokonon et al., 2019; Egbendewe-Mondjozo et al., 2017; Pilo, 2014). In the tropics and particularly in Africa, climate change is most often considered to be highly detrimental to livelihoods in the agricultural sector (Dinar et al., 2008). Africa is subject to a highly variable and unpredictable climate. This weakens African agricultural systems that no longer respond to current climate pressures (Yegbemey et al., 2014). Already, Kurukulasuriya et al. (2006) highlighted the continent's high vulnerability to climate change due to the high dependence of economies on agriculture and the limited adaptive capacities of populations.

A firm to ensure its growth in a continuous manner, seeks to use the best available technology or innovate taking into account the economic context (Suri 2011; Hailu et al. 2014). In a context marked by the law of diminishing returns, in order to cope with declining productivity, a firm must improve or change its production technology by the most productive or efficient one possible; this is the adoption of technological innovations. New technologies are more likely to be adopted in response to economic scarcity and opportunity (Hicks, 1932; Habakkuk, 1962; Allen, 2008; Acemoglu, 2010). Similarly, when the environment of the production system changes, it is necessary to adjust the production technology to accommodate this change (Easterling, 1996 and Sunding and Zilberman, 2001). Clearly, the motivation for any decision to adopt an agricultural technology lies in the desire to improve productive performance. The success of agricultural transformation worldwide has been largely attributed to improved agricultural technologies such as fertilizers, improved seeds, and soil and water conservation (Johnston and Kilby, 1975; Mellor, 1976; Gabre-Madhin and Johnston 2002). The adoption of these technologies offers opportunities to not only increase agricultural productivity and income (Feder et al., 1985), but also to protect against climate risks.

For developing countries, the contribution of improved technologies to agricultural productivity is well documented (Sunding and Zilberman, 2001; and Doss, 2006). The process of technological adjustment to can be affected by farmers' expectations of future climate change as well as by expected price changes.

Technology adjustment that occurs in response to environmental and market shocks has been widely studied and well documented in the literature (Lucas 1967; Caballero 1994; Hamermesh and Pfann 1996; Hall 2004; Lambert and Gong 2010). The existence of risks associated with the adoption of new technologies can reduce productive performance and delay farmers' 


\section{Perception of Climate Risks and Issues of Adoption of Resilient Technologies by Farmers in Togo}

response to these shocks. However, the response of farmers to environmental shocks such as climate change can affect the adjustment costs and risks of introducing new technologies in the technological adjustment process has received relatively little attention.

Indeed, the change in climate observed over the last thirty years, at the global level, is one of the major challenges of our time. It is characterized by the resurgence of extreme phenomena such as droughts and floods, rising temperatures, increased variability of rainfall and characteristics of agricultural seasons (IPCC, 2007). As early as the Rio de Janeiro summit in 1992, the international community recognized the reality of the danger, through the report by the British economist Nicolas Stern. Indeed, this report compares the future consequences of climate change to those of the first and second world wars and the 1929 crisis combined, and estimates the costs of this change at 5,500 billion euros and 5\% of future GDP in the world if nothing is done. Climate change is therefore a major threat to the environment and agricultural development worldwide and especially in Africa. Thus, for Egbendewe et al (2016), adaptation measures must be rapidly designed to reduce the impact of climate change on food security, especially in countries located in the tropics. For the same authors, one way to address food insecurity issues besides the required emission reduction efforts may be through food trade between countries.

Thus, a rich literature is provided in the logic of climate change adaptation (Rashid et al., 2008; Yesuf et al .,2008 and Asfaw, 2013). Apata (2010) uses a multinomial model and a stochastic simulation model to show that adaptation measures have a significant impact on the agricultural productivity of Nigerian farmers. In the same vein, Dédehouanou (2016) showed that $84 \%$ of Nigerian smallholder farmers have adopted one or more strategies to cope with climate change (temperature, rainfall). If the importance of adaptation to climate change is perceived and clearly articulated, it must arguably be said that the ability to perceive change plays a driving role in the adaptation process. Adaptation to climate change is a process that initially requires producers to perceive that the climate has changed and then identify useful adaptations to implement (Mustapha et al .,2012). This last aspect has attracted the attention of many. Gnanglè et al (2011) have shown that the capacity to adapt to climate change is strongly related to the capacity of a farmer to perceive it. Thus, the main question of this research is to know how Togolese farmers react to climate risks. These are: what determines their capacity to perceive climate risks and how do they take into account the endogenous risks related to the adoption of new technologies in their adaptation process to climate change?

The objective of this research is to analyze the decision to adopt innovative technologies by Togolese farmers in order to strengthen their resilience to climate change. Specifically, the aim is to analyze the capacity to perceive climate risks and their implication in the decision to adopt resilient technologies, and then to analyze the consideration of yield loss risks related to the adoption of new technologies in the process of adaptation to climate change by Togolese farmers. The contribution of this research is to simultaneously take into account the involvement of upstream and downstream risks in the process of adopting new agricultural technologies. Following this work, we will present session 1 titled material and method, then we will present in session 2 the results and discussions, then we will end with a conclusion.

\section{MATERIAL AND METHOD}

Our modeling of technology adoption choice through the capacity to perceive climate change is based on the work of Maddison (2007) and Gbetibouo (2009), which was taken up by Yegbemey et al. The consideration of endogenous risks is inspired by the work of Chavas (2003). To better understand the design, we will present the theoretical model on the determination of the factors of perception and adaptation and then expose the adapted empirical framework. We will close this session with the presentation of data and some descriptive statistics.

Theoretical model on the determination of factors of perception and adaptation.

Given that farm households in Togo and elsewhere in the developing world produce under conditions of uncertainty and large market imperfections, the study adopted an expected utility maximization framework. Production risk was represented by the stochastic term $\varepsilon$, whose distribution, $G($.) was exogenous to the actions of the farm household. Since improved varieties are among the most important inputs in the agricultural production process of smallholders, the household production function was presented as:

$$
q=f\left[h(\alpha) x_{c}, \boldsymbol{x}, \boldsymbol{I}, \boldsymbol{\epsilon}\right]
$$

While taking risk aversion into account, if $r$ and $p$ represent input and output prices respectively, the problem of a risk averse household maximizing expected utility of gross income is: 


$$
\begin{aligned}
& \max _{X} E[U(\pi)] \\
& =\max _{x} \int_{0}^{q}\left[U \left(p f\left[X_{S}, X_{f}, X_{0}, \varepsilon\right]-r_{f} X_{f}-r_{S} X_{S}\right.\right. \\
& \left.\left.-r_{0} X_{0}\right)\right] d G(\varepsilon)
\end{aligned}
$$

Where $U($.$) Is the Von Neumann-Morgenstern utility function. E$ is the expectation while $\varepsilon$ captures all unobserved household heterogeneity such as unreported farm management capacity, land fertility, risk preferences and risk management measures, and the discount rate that could affect input use and farm productivity.

Since $r$ and $p$ are not random, the necessary first-order condition for the variable the improved seed was specified as:

And

$$
E\left[r_{f} U^{\prime}\right]=E\left\{p \frac{\partial f\left[X_{s}, X_{f}, X_{0}, \varepsilon\right]}{\partial x_{f}} U^{\prime}\right\}
$$

$$
\begin{aligned}
& \frac{r_{f}}{p} \\
& =E\left\{\frac{\partial f\left[X_{S}, X_{f}, X_{0}, \boldsymbol{\varepsilon}\right]}{\partial x_{f}}\right\} \\
& +\frac{\operatorname{cov}\left[U^{\prime}, \partial f\left[X_{S}, X_{f}, X_{0}, \boldsymbol{\varepsilon}\right] / \partial x_{f}\right]}{E\left[U^{\prime}\right]}
\end{aligned}
$$

where $U$ 'is the change in income utility due to a change in income. In other words $U^{\prime}=\partial U(\omega) / \partial \omega$.

Because the new technology is more efficient, we expect risk-averse farmers who bear higher profit uncertainty to have a higher probability of adoption, in order to protect themselves from the risk of adverse weather conditions (Kebede et al. 1990; Foster \& Rosenzweig 2010).

Now assume that future profit streams after adoption are not known with certainty because of either the lack of knowledge of the exact performance of the new irrigation technology, or the higher probability that the use of the technology is not appropriate for the actual conditions, or that the market does not offer the sales opportunities. In addition, there are sunk costs associated with purchasing the new technology (there is a fixed investment cost and some irreversibility in the decision). These arguments imply that additional information could have positive value (Dixit and Pindyck 1994). Farmers may prefer to delay adoption in order to obtain more information about the new device. Therefore, an additional premium may be part of the adoption condition. The farmer will adopt if:

$$
E\left[U\left(\omega^{i}\right)\right]-E\left[U\left(\omega^{0}\right)\right]>V I
$$

where $\mathrm{VI} \geq 0$ represents the value of the new information to the representative farmer, which is expected to depend on the fixed cost of the investment, the level of uncertainty in using the new technology, and the existence of the market and the farmer's own characteristics.

Antle $(1983 ; 1987)$ provides a flexible way to estimate equations 3 and 4 that requires only information on prices, input quantities, and other observable variables. The approach is equivalent to maximizing the expected utility of farm income over any input to maximizing a function of the moments of the distribution of $\varepsilon$. The moments themselves have $X_{s}$ as arguments (Antle, 1983; 1987). We therefore calculated the first four moments of the stochastic production function and included them as covariates in the analysis of improved seed adoption decisions. The study hypothesized that a household's adoption decision on improved seed (IS) was intimately related to the ability to perceive climate risks. Both of these phenomena depended on factors such as plot characteristics (Pc), household characteristics (hc), agro-ecological characteristics (AEc) and other random factors simultaneously or not (Pender and Kerr, 1998; Shiferaw and Holden, 1999; Doss, 2007; Yesuf and Kohlin, 2008). The theoretical model of adoption decisions of improved rice varieties and fertilizers was therefore specified as follows:

$$
S A_{h a}=f\left(\begin{array}{c}
\operatorname{Per}_{i}, p_{f}, L_{o s}, A_{c m}, \text { InfoM }, \\
P c, M c, A E c, C r, \mu_{S A R}
\end{array}\right)(6)
$$

Equations 6 represent the observed binary variable that reflects the latent net benefit, SA; from adoption of improved seed varieties.

\section{The econometric model adopted}

The regression model in this study was inspired by recent work by Yegbemey et al. (2014) who studied adoption in relation to perception based on Logit and Probit models with the following general form:

$$
S A_{i}={ }_{i} f(Z) \quad \text { (7) }
$$




\section{Perception of Climate Risks and Issues of Adoption of Resilient Technologies by Farmers in Togo}

Where $S A_{i}$ and $Z_{i}$ represent respectively the adaptation decision of producer $i$ and a set of demographic and socio-economic characteristics of the same producer $i$.

Considering the assumption of the perceptionadaptation link, the simplest way to integrate the producers' perception $(P)$ in the previous model is to express it as:

$$
S A_{i}=f\left(Z_{i}, \operatorname{Perc}_{i}\right)
$$

The specification of two separate models - an adoption model (equation 8) and a perception model (equation 9) - appears to be an alternative that would limit the estimation biases:

$$
\begin{aligned}
& S A_{i}=f\left(Z_{i}\right) \\
& \operatorname{PerC}_{i}=f\left(Y_{i}\right)
\end{aligned}
$$

Where $Y_{i}$ represents a set of demographic and socioeconomic characteristics of the same producer $i$ that could be the same or different from Zi. This new formulation, while it somewhat eliminates the endogeneity bias associated with perception, does not take into account the initial assumption that the adoption of agricultural technologies in the face of stimuli, such as climate change, is only intelligible in terms of their conception of such change. According to Maddison (2007), perception is a prerequisite for adaptation. In other words, one must perceive before adapting. The problem is therefore no longer one of endogeneity, but rather of selection: adaptation if there is perception. Thus, as proposed by Maddison (2007) and Gbetibouo (2009), a selection model such as Heckman's Probit model allows for a better exploration of the adaptation decision of producers in relation to their perception. In doing so, the general model becomes:

$$
S A i=f(Z i)
$$

If and only if:

$$
\operatorname{Perc}_{i}=f\left(Y_{i}\right)
$$

The form thus defined is based on two sub-models: the However, still in the light of the theoretical framework, output model or adaptation model whose dependent perception itself appears to be an endogenous variable variable is adoption (SA) and the selection model (a function of a number of characteristics specific to whose dependent variable is perception (Perc). the individual). Therefore, the estimation of equation 7 is subject to endogeneity bias. Under these conditions, Allowing for endogenous risk implies that the adoption condition in relation 5 requires that the following inequality holds:

$$
E\left[U\left(\omega^{i}\right)\right]-E\left[U\left(\omega^{0}\right)\right]-V I>0
$$

At the time of the survey, we observe farmers in a unique situation (adoption or non-adoption), so we cannot estimate this structural equation. Instead, we estimate a reduced form of this equation and focus on the impact of risk in explaining the adoption decision. First, to avoid specifying a functional form for the yield probability function (-), the risk distribution $\mathrm{G}($ ), and the farmer's risk preferences (i.e., the utility function $U(-))$, we use a moment approach that allows a flexible representation of production risk (Antle 1983, 1987; Antle and Goodger 1984). Production risk and thus uncertainty about profits are accounted for in the adoption model by using the sample moments of the profit distribution as explanatory variables for the farmers' decision. Our dataset has the great advantage of collecting information on farmers who had just adopted the new technology. Specifically, farmers were interviewed at the time the decision to adopt/not adopt was made. Thus, the profit function was not yet affected by the adoption decision and for this reason, profit moments can be assumed to be exogenous to the farmers' decision. Second, as explained earlier, there is an additional source of risk that arises from the uncertainty about future profit streams that is introduced into the production process by the use of the new equipment.

The cost of this uncertainty is represented by a premium (VI) in the above equation, indicating the value of seeking additional information. In our empirical model, the role of information on the adoption decision will be measured through the following proxy variables that determine the farmer's human capital: the education level of the household head, the collection of general information on active agriculture and, the number of extension visits. All three variables are assumed to be positively correlated with farmers' level of information about the new equipment. According to human capital theory, innovative capacity is closely related to these variables (Kihlstrom 1976), since these characteristics are associated with farmers' resource allocation skills (Nelson and Phelps 1966; Schultz 1972; Huffman 1977). Information gathering, whether or not it refers to the innovation itself, should improve resource allocation skills and increase the efficiency of adoption decisions. A farmer with a high level of resource allocation skills will make more accurate predictions of future yields and profitability and thus make more effective adoption decisions (Stigler 1961; Huffman 2001). Similarly, imperfect information about new technologies can lead to risks associated with adopting the innovation that can increase the possibility of making mistakes.

The estimation procedure consists of two steps. First, we compute the first four sample moments of each farmer's profit distribution, namely the mean, variance, skewness, and kurtosis coefficients. Second, we incorporate the estimated moments into 


\section{Perception of Climate Risks and Issues of Adoption of Resilient Technologies by Farmers in Togo}

a traditional discrete choice model, along with other farmers' characteristics and farmer information variables, to analyze how production risk and information affect the decision to adopt a technological innovation. The first four moments of the profit distribution are derived using a sequential estimation procedure (Kim and Chavas, 2003). In the first step, the return is regressed on the contemporaneous input variables to provide an estimate of the "average" effect. The model 13 has the following general form:

$$
\omega_{i}=\psi\left(x_{c i}, \boldsymbol{x}_{\boldsymbol{i}}, \mathbf{z}_{i}, \boldsymbol{\beta}\right)+u_{i}
$$

Where $i=1, \ldots N$ denotes the individual farmers in the sample, $\omega$ is the yield per hectare, $x$ is the vector of variable inputs (labor, intermediate inputs), $x_{c}$ is the seed used, $\mathrm{z}$ is the vector of additional variables, including farmer characteristics (age and additional farmer income unrelated to farming activities) and farmspecific characteristics (geographical location, and aridity). $\mathrm{u}$ is the usual independently distributed error term. Under expected profit maximization, the explanatory variables are assumed to be exogenous and thus ordinary least squares (OLS) estimation provides consistent and efficient estimates of the parameter vector. Then, the $\mathrm{ji}^{\mathrm{e} m e}$ central moment of return $(\mathrm{j}=2, \ldots, \mathrm{M})$ conditional on input use is defined as:

$$
\mu_{j}(.)=E\left\{\left[\omega(.)-\mu_{1}\right]^{j}\right\}
$$

where $\mu_{1}$ represents the mean or first moment of performance. Thus, the estimated errors of the mean effect regression $\hat{\mu}=\omega-$ $\psi\left(x_{c i}, \boldsymbol{x}_{i}, \mathbf{z}_{i}, \boldsymbol{\beta}\right)$ are estimates of the first moment of the earnings distribution. The estimated errors $\hat{\mu}$ are then squared and regressed on the same set of explanatory variables:

$$
\hat{\mu}_{i}^{2}=g\left(x_{c i}, \boldsymbol{x}_{i}, \mathbf{z}_{i}, \boldsymbol{\delta}\right)+\tilde{u}_{i}
$$

Applying OLS to this equation provides consistent estimates of the parameter vector and the predicted values $\hat{\mu}_{i}{ }^{2}$ are consistent estimates of the second central moment of the earnings distribution (i.e., the variance) (Antle 1983). We follow the same procedure to estimate the third and fourth central moments, using the estimated errors raised to the power of three and four, respectively, as dependent variables in the model. The four estimated moments are then incorporated into a discrete model of technology adoption with structural and demographic characteristics of the farmers.

Recall that the farmer will choose to adopt modern technology if and only if:

$$
Y_{i}^{*} \equiv E\left[U\left(\omega^{i}\right)\right]-E\left[U\left(\omega^{0}\right)\right]-V I>0 .
$$

$Y_{i}{ }^{*}$ is an unobservable random index for each farmer that defines his or her propensity to adopt a new improved seed technology. For estimation purposes, let us note

$$
Y_{j i}=Z_{j i}^{\prime} \alpha_{j}+m_{j i}^{\prime} \alpha_{j}^{m}+[m \times K]_{j i}^{\prime} \alpha_{j}^{K}+v_{j i}
$$

The indirect utility of farmer $\mathrm{i}$ adopting at level $\mathrm{j}$.

The vector $z$ is a vector of regressors including all structural and demographic characteristics, $m$ is the vector of the first four profit moments that introduce uncertainty into the model, and $[\mathrm{m} \times \mathrm{k}]$ denotes the vector containing the interactions between the four moments and the human capital variables. $\alpha$ is a vector of parameters to be estimated and $v$ is the usual error term.

The estimated production risk factors were then incorporated into improved variety adoption models (Equation 11) that were estimated as selection probit to handle the simultaneity of technology adoption ad climate risk perception decisions. A similar approach was used by Feder et al. (1985), Feder and Onchan (1987) and Yesuf and Kohlin (2008). The model was specified as follows:

$$
\begin{aligned}
& S A_{h a}= \\
& f\left(\begin{array}{c}
p_{f}, L_{o s}, A_{c m}, \text { InfoM }, P c, M c, \\
A E c, C r, m_{j i}^{\prime} \alpha_{j}^{m}+\left[\begin{array}{ll}
m x & K
\end{array}\right]_{j i}^{\prime} \alpha_{j}^{K} \mu_{S A R}
\end{array}\right)
\end{aligned}
$$

If and only if :

$$
\operatorname{Perc}_{i}=f\left(Y_{i}\right)
$$

\section{Data and descriptive statistics.}

This study will use data collected in the five (05) regions of Togo by the Direction des Statistiques Agricoles de l'Informatiques et de la Documentation (DSID). A total of 545 farmers were interviewed on their socioeconomic characteristics as well as on their plots and their farming practices. According to the analysis, men represent $72 \%$ against $28 \%$ of women. As for the level of education, the data reveal that $37 \%$ of the farmers have a primary level of education, i.e. 204 , and $31 \%$ a secondary level $(170$ farmers). We record $91 \%$ of farmers who claim to be married, against $9 \%$. Given the importance of training farmers in the mastery of agricultural practices, the study was interested in knowing whether farmers are actually trained in their profession, and $69 \%$ said they had received agricultural training on a sample of 546 producers. This compares with $31 \%$ of producers who had not received training. With regard to technical support from support and extension services, only $23 \%$ of producers receive this technical support. 


\section{Perception of Climate Risks and Issues of Adoption of Resilient Technologies by Farmers in Togo}

Belonging to a Production Organization strengthens networking and provides enormous benefits to member farmers. The analysis of the data reveals that more than half (56.3\%) of the producers belong to a PO. In addition, $44 \%$ of the respondents have access to credit to finance their activities. And that most of the plots studied are not irrigated (about 93\%).

Table 1. Explanatory variables considered

\begin{tabular}{|c|c|c|c|}
\hline \multirow[t]{2}{*}{ variable } & \multirow[t]{2}{*}{ Description } & \multicolumn{2}{|c|}{ Expected signs } \\
\hline & & adoption & perception \\
\hline male & $\begin{array}{l}\text { Describes the gender of the respondent, this variable takes the value } 1 \text { if } \\
\text { the respondent is male and } 0 \text { otherwise. }\end{array}$ & + & + \\
\hline Age & This variable indicates the age of the respondent & + & + \\
\hline Not educated & $\begin{array}{l}\text { Indicates if the respondent is educated or not. It takes the value of } 1 \text { if he } \\
\text { is not educated and } 0 \text { if he is. }\end{array}$ & - & - \\
\hline primary & $\begin{array}{l}\text { Indicates the level of education of the respondent, it takes the value } 1 \text { if } \\
\text { the respondent has a primary level and } 0 \text { otherwise }\end{array}$ & + & + \\
\hline bride & $\begin{array}{l}\text { This variable indicates the marital status of the respondent mainly married } \\
\text { and takes the value } 1 \text { if the respondent is married and } 0 \text { otherwise. }\end{array}$ & + & + \\
\hline household size & $\begin{array}{l}\text { Indicates the household size of the producer, it takes the value } 1 \text { if the } \\
\text { household size is }<5 \text { and } 2>=5\end{array}$ & + & + \\
\hline agriculture & $\begin{array}{l}\text { Indicates the main activity of the respondent, it takes the value } 1 \text { if the } \\
\text { respondent is a farmer and } 0 \text { otherwise }\end{array}$ & + & + \\
\hline land heritage & Indicates the level of land holdings. It is evaluated in ha. & + & + \\
\hline Farming_experience & $\begin{array}{l}\text { Describes the number of years of experience of the rice farmer, it takes the } \\
\text { value } 1 \text { if the rice farmer has an experience }<\text { to } 5 \text { years and } 2 \text { if the number } \\
\text { of years is }>=5 \text { years }\end{array}$ & + & + \\
\hline training & $\begin{array}{l}\text { The training variable indicates whether the producer has received training } \\
\text { in rice cultivation, and takes the value } 1 \text { if yes and } 0 \text { if not. }\end{array}$ & + & + \\
\hline fort_capital_objective & $\begin{array}{l}\text { Indicates the level of objective capital of the farmer, it takes the value of } 1 \\
\text { if the level is strong and } 0 \text { if not }\end{array}$ & + & + \\
\hline low_capital_goal & $\begin{array}{l}\text { Indicates the level of objective capital of the farmer, it takes the value of } 1 \\
\text { if the level is low and } 0 \text { if not }\end{array}$ & - & - \\
\hline fort_cap_sub & $\begin{array}{l}\text { Indicates the level of subjective capital of the farmer, it takes the value of } \\
1 \text { if the level is strong and } 0 \text { if not }\end{array}$ & + & + \\
\hline low_cap_sub & $\begin{array}{l}\text { Indicates the subjective capital level of the farmer, it takes the value of } 1 \text { if } \\
\text { the level is low and } 0 \text { if not }\end{array}$ & - & - \\
\hline pluvial system & $\begin{array}{l}\text { Indicates the production system practiced by the respondent, it takes the } \\
\text { value } 1 \text { if the respondent practices the rainfed system, } 0 \text { otherwise }\end{array}$ & - & - \\
\hline smallholder & $\begin{array}{l}\text { This variable indicates the size of the farm. It takes the value of } 1 \text { if the farm } \\
\text { is smaller than one ha and } 0 \text { if not }\end{array}$ & - & - \\
\hline large operator & $\begin{array}{l}\text { This variable indicates the size of the farm. It takes the value of } 1 \text { if the farm } \\
\text { is bigger than two ha and } \\
0 \text { if not }\end{array}$ & + & + \\
\hline nutrient retention & $\begin{array}{l}\text { This variable indicates the type of soil used by the producer, it takes the } \\
\text { value } 1 \text { if the soil is able to retain nutrients and } 0 \text { otherwise }\end{array}$ & - & - \\
\hline Drainage capacity & $\begin{array}{l}\text { This variable describes the nature of the soil. It takes the value of } 1 \text { if the } \\
\text { soil has a high drainage capacity and } 0 \text { if not }\end{array}$ & + & + \\
\hline low mechanization & $\begin{array}{l}\text { Indicates the level of mechanization, it takes the value } 1 \text { if the } \\
\text { mechanization is low and } 0 \text { otherwise }\end{array}$ & - & - \\
\hline OP membership & $\begin{array}{l}\text { It indicates if the producer belongs to a producer organization and takes } \\
\text { the value } 1 \text { if yes and } 0 \text { otherwise. }\end{array}$ & + & + \\
\hline technical support & $\begin{array}{l}\text { Indicates whether the respondent received technical support; } 1 \text { if yes and } \\
0 \text { otherwise }\end{array}$ & + & + \\
\hline
\end{tabular}


Perception of Climate Risks and Issues of Adoption of Resilient Technologies by Farmers in Togo

\begin{tabular}{|l|l|l|l|}
\hline Access to credit & $\begin{array}{l}\text { This variable indicates whether the farmer has access to credit. It takes the } \\
\text { value of } 1 \text { if yes and } 0 \text { if no }\end{array}$ & + \\
\hline $\begin{array}{l}\text { Market Opportunities } \\
\text { Village_Market }\end{array}$ & $\begin{array}{l}\text { Indicates the type of outlet, it takes the value } 1 \text { if it is on the village market } \\
\text { and } 0 \text { otherwise }\end{array}$ & - \\
\hline $\begin{array}{l}\text { Opportunities Formal } \\
\text { Aggregator }\end{array}$ & $\begin{array}{l}\text { Indicates the type of contract, it takes the value } 1 \text { if it is a formal contract } \\
\text { and } 0 \text { otherwise }\end{array}$ & + & + \\
\hline SAR & $\begin{array}{l}\text { This variable indicates the adoption of improved seed by the farmer, and } \\
\text { takes the value } 1 \text { if the farmer uses improved seed and that seed comes } \\
\text { from ICAT or ITRA and } 0 \text { otherwise. }\end{array}$ & & \\
\hline Perception & $\begin{array}{l}\text { Indicates the collection of the CC; it takes the value } 1 \text { if the producer } \\
\text { declares to have collected the CC and } 0 \text { otherwise. }\end{array}$ & & \\
\hline
\end{tabular}

Source: Author, based on survey data.

\section{RESULTS AND DISCUSSION}

The table summarizes the results of the selection model (Heckman's Probit) used to determine the main factors influencing farmers' ability to perceive climate risk and the adoption of improved rice seed. This model is used by incorporating the four central moments to analyze the effect of endogenous risk related to the adoption of the new technology. This allows us to analyze the risks upstream and downstream of the decision to adopt improved seeds. The estimated model is globally significant at the $5 \%$ statistical threshold and the Wald test is significant, reflecting the acceptance of the hypothesis of simultaneity of decision and perception. Thus, the ability to perceive climatic risks strongly determines the decision to adopt an innovative technology to protect oneself from the potential perceived risk. As was the case in Benin (Yegbemey et al., 2014), Burkina (Ouédraogo et al., 2010) and Niger (Dédehouanou, 2016). If perception is considered the main determinant of the adoption of innovative technologies, it is important to understand what determines both the ability to perceive and other explanatory factors of the decision to adopt these technologies, keeping in mind that a new technology is in itself a carrier of risk.

\section{Determinants of climate risk perception}

Certain factors were diagnosed to analyze their influence on the capacity to perceive climate risks. In this case, it is particularly the risk of drought and the risk of flooding. Beyond the socio-economic and institutional characteristics often mentioned in the literature, the analysis here integrates the characteristics of the plots.

\section{Socio-economic characteristics}

Overall, socio-economic characteristics have little influence on climate risk perception ability. Only marital status, agricultural education and subjective capital level significantly influence the climate risk perception capacity of the farmers studied. Indeed, although it is expected that married farmers would have a greater ability to perceive climate risk due to their level of responsibility, the results here indicate the opposite. Single farmers perceive risks better than married farmers. This result can be explain ed by the fact that the latter's level of responsibility requires them to diversify. Thus, they do not concentrate on the sole agricultural activity at the risk of putting their socioeconomic vulnerability at risk.

Table 2: Results of the heckman selection probit model

\begin{tabular}{|c|c|c|c|c|}
\hline \multirow[b]{2}{*}{ variable } & \multicolumn{2}{|c|}{ Adoption of SAR } & \multicolumn{2}{|c|}{ Perception of climate risk } \\
\hline & Coefficients & std. Err & $\overline{\text { Coeficient }}$ & std. Err \\
\hline \multicolumn{5}{|c|}{ Socio-economic characteristics } \\
\hline male & -0.208 & 0.192 & -0.245 & 0.159 \\
\hline Age & -0.0139 & 0.009 & 0.007 & 0.007 \\
\hline Not educated & $-0.548 * *$ & 0.271 & 0.214 & 0.199 \\
\hline primary & 0.069 & 0.185 & 0.196 & 0.153 \\
\hline bride & & & $-0.331^{*}$ & 0.183 \\
\hline household size & 0.006 & 0.023 & -0.012 & 0.017 \\
\hline agriculture & 0.388 & 0.344 & -0.287 & 0.268 \\
\hline land heritage & $0.143 * *$ & 0.068 & & \\
\hline Farming_experience & -0.002 & 0.011 & -0.005 & 0.008 \\
\hline
\end{tabular}


Perception of Climate Risks and Issues of Adoption of Resilient Technologies by Farmers in Togo

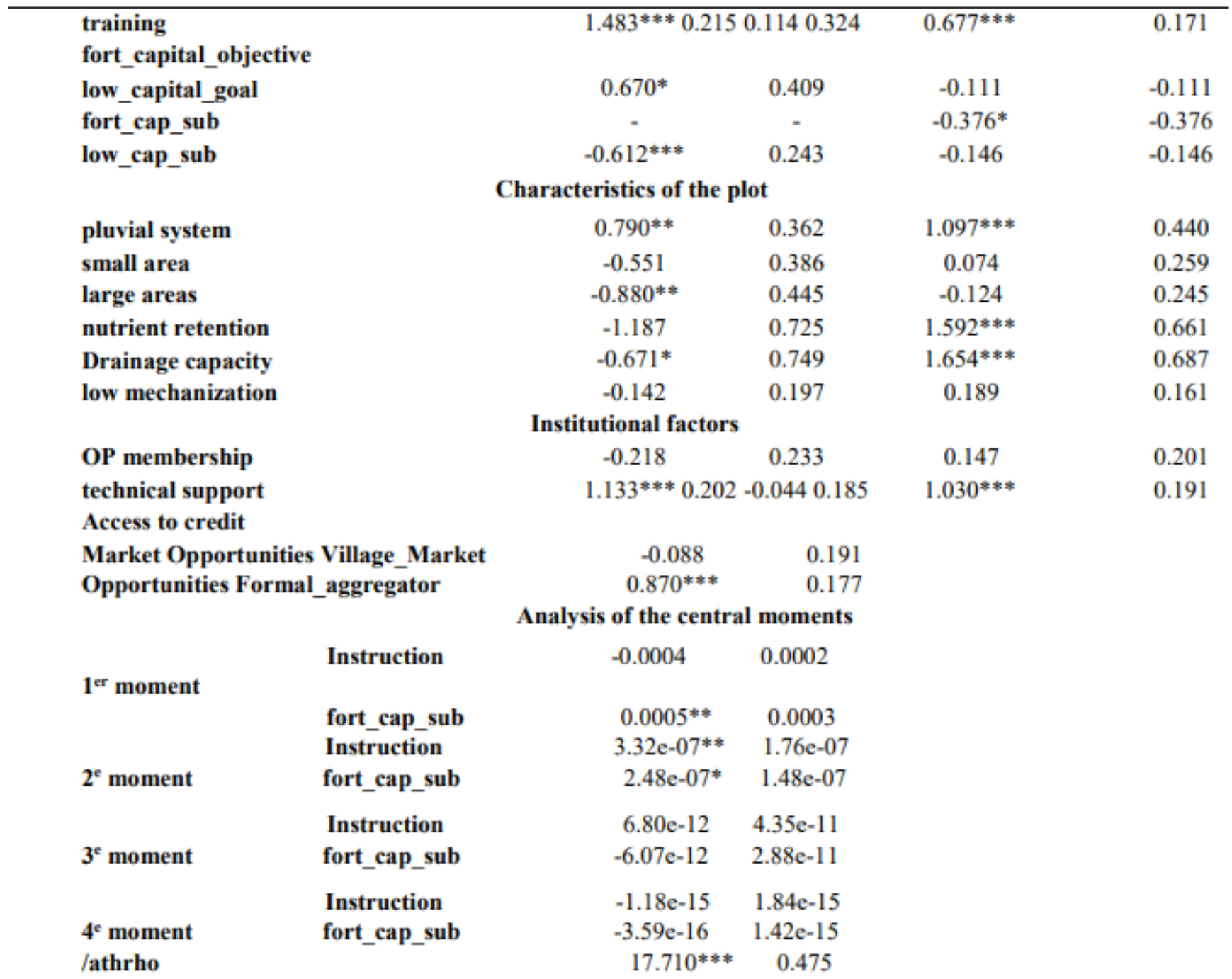

LR test of indep. eqns. $($ rho $=0)$ : $\operatorname{chi} 2(1)=4.96^{* *}$

In the same sense, farmers with high subjective capital are less likely to perceive manifestations of climate risks. Subjective capital here expresses the level of skill and leadership. This variable is proxied by experience with agricultural projects and programs and proximity to an urban center. Thus, farmers in urban proximity perceive less risk of drought (only $28 \%$ versus $64 \%$ for those who are far away). Similarly, farmers who have benefited from an agricultural project perceive less climatic risk (about $20 \%$ ) than those who have not benefited (38\%). These projects and programs improve their socio-economic situation and reduce their level of climate vulnerability. On the other hand, farmers who have received training in agriculture have a greater capacity to perceive climate risks. Similarly, the technical support provided by the accompanying services improves their ability to perceive climate risks. This support not only allows for the mastery of technical itineraries, but also climatic information. This contributes to strengthening their ability to read the evolution of the climate.

\section{Factors related to the parcels of land}

Beyond the socio-economic characteristics of the farmers, let us say that the characteristics of the plots were integrated to analyze their influence on the perception capacity. Of all the characteristics involved, only the drainage capacity, the nutrient retention capacity of the plots and the fact that the plot is irrigated or not influence the farmers' ability to perceive climate risks. It should be noted that farmers operating on nonirrigated plots perceive climate risks very quickly than those operating on irrigated plots. Similarly, plots characterized by high drainage capacity and those with high nutrient retention capacity significantly and positively influence farmers' ability to perceive climate risks. It must be said that the owners of plots with high nutrient retention capacity clearly have control over their production system. Thus, they are very sensitive to losses related to climate risks. Thus, it is concluded that socioeconomic factors and plot characteristics significantly influence the ability to perceive climatic risks, which in turn influences the decision to adopt improved seeds. It is then necessary to look at the determinants of the latter. 


\section{Perception of Climate Risks and Issues of Adoption of Resilient Technologies by Farmers in Togo}

\section{Determinants of improved seed adoption}

The determinants of resilient technology adoption have been the subject of a wealth of research. Beyond socioeconomic and institutional factors, farm-level factors are involved in this analysis.

\section{Socio-economic factors in the adoption of improved seeds}

i. Human capital and adoption decisions

One might imagine that farmers with higher levels of education have a better understanding of the technology, and thus are more willing to judge its usefulness and adoption. Indeed, the table shows that farmers with no education are less likely to adopt the technology. In the same vein, many studies have also been able to show a positive correlation between adoption decisions and level of education in Sub-Saharan Africa (Kebede et al. 1990; Chirwa 2005). Other authors find that the level of education is not only a determining factor on adoption decisions, but also on the intensity of use of the new technology (Croppenstedt et al. 2003). Also, if the new technology requires higher cognitive ability and or experience, it will be expected to be less accepted by farmers with low human capital. Gollin et al. (2014) show that low human capital among farmers is known and it is even more accentuated in developing countries. The work of Kebede et al. (1990) in Ethiopia, shows the link between the level of education, work experience and adoption decisions of new technologies among farmers. All this reinforces our findings that farmers with strong objective capital readily engage in innovation initiatives. This is reinforced by participation in agricultural training sessions.

\section{ii. Farm household assets}

Many studies have been able to show the positive correlation between the level of wealth of the farm household and the choice to adopt a new technology (Kebede et al. 1990; Alene \& Manyong 2006; O'Gorman 2006; Hailu et al. 2014; Lambrecht et al. 2014). Farming households in Sub-Saharan Africa, generally characterized by low purchasing power, may have less incentive to undertake a new technology due to investment needs and their greater vulnerability to associated risks. Also, for these poor farm households, acquiring the new technology may come at the cost of transiently foregoing other needs, making the adoption decision even more difficult, especially if there is no assurance that the technology will improve the initial situation. In contrast, wealthy farm households may be tempted to play the game by devoting a portion of their income to acquire the new technology despite the associated risk. Thus, our results confirm this assertion. Indeed, our results show that farmers characterized by a high level of wealth are more likely to adopt the technology in question. o Institutional factors and the adoption decision

\section{Market and product valuation factors}

Issues related to conservation (Ricker-Gilbert \& Jones

2015) and market valuation (Alene \& Manyong 2006, Hailu et al. 2014) are believed to influence the use of new technologies. Thus, the analysis of the results reveals that farmers who manage to secure the market through the signing of formal contracts with aggregators readily adopt improved seeds. Indeed, if the new technology creates surpluses that need to be transported several kilometers in order to be valued, the technology will be less effective. Thus, Sub-Saharan Africa, which is characterized by impractical transportation systems, especially in rural areas, is losing efficiency in the use of new technologies in agriculture. Furthermore, better organization of actors, especially via communication tools such as cell phones, would allow for improved market practices in order to better benefit from the adoption of new technologies (Baumüller 2012).

\section{The Implementation and Monitoring Approach}

If the adoption of new technologies in agriculture can be influenced by all of the above-mentioned factors, it is important to take into account the role that the agents in charge of the extension of the technological tool could play (Feder et al. 1985). The way in which these agents collaborate with farmers and their level of mastery of this tool will condition the decisions of its adoption by farmers. In this sense, the results show that farmers who have benefited from the support services tend to adopt the technology better. Thus, strengthening extension services would also allow for better support to farmers in the process of adopting and appropriating the technological tool (O'Gorman 2006; Ricker-Gilbert \& Jones 2015).

\section{Considering risk in the process of technology adoption in agriculture}

Risk is one of the main factors for rejecting innovation (Feder 1980, Ghadim et al. 2005). Many works have highlighted the weight of risk aversion in the innovation adoption process and reveal that the level of risk aversion of farmers is generally higher than that of entrepreneurs in other agricultural sectors (Harrison et al. 2007; Hellerstein et al. 2013). This is because farm operators are used to experiencing risk and are overall more risk tolerant, but like all entrepreneurs, they are more sensitive to the risk of loss (Bocqueho et al. 2011). The central role of risk in the farmer's decision is highlighted in this research through the importance of the central moments in the sample. The first and second moments, which approximate expected yield and yield variance, are highly significant. The third moment, which approximates yield skewness, and the fourth moment are not statistically significant. 


\section{Perception of Climate Risks and Issues of Adoption of Resilient Technologies by Farmers in Togo}

These results indicate that the higher the expected yield, the greater the likelihood that a farmer will decide to adopt a new improved seed technology, as he expects to be able to afford the adoption of new technologies that improve resistance to attack and water stress. In addition, the greater the variance in yield (and the greater the likelihood of facing extreme yield values), the greater the likelihood of adopting new improved seed technologies. This allows farmers to reduce production (yield) risk through shortening the production cycle. This result provides evidence that farmers invest in new technologies as a way to hedge against inputrelated production risk. Finally, the statistical insignificance of the third yield moment indicates that farmers do not consider downward yield uncertainty when deciding to adopt a new improved seed technology. In other words, although the choice of improved seed technology is relevant to addressing production risk (as measured by yield variance), these results suggest that technology choice does not affect exposure to downward yield uncertainty.

The interaction of the four profit moments with education, and the level of subjective capital allows us to test whether the amount of information accumulated by the farmer (through education, and the level of subjective capital) affects the farmer's response to risk. It turns out that higher education and the higher level of subjective capital increase the farmers' response to the variation of the first and second yield moment. This result indicates that the more educated and skilled the farmer is, the more sensitive he is to the parameters that affect the expectation and variance of farm yield. As a result, his likelihood of adopting a new technology to protect himself against outlier activity in his yield distribution increases.

\section{CONCLUSION}

In this paper, we develop a theoretical model to simultaneously describe the adoption of improved seed technology and the climate risk perception capacity of farmers facing production risks and incomplete information about the new technology. The adoption condition is derived from the assumptions of upstream climate risk perception and downstream farmer risk aversion, and assuming that uncertainty can arise from two sources: the randomness of climatic conditions and the uncertainty of future yield streams associated with the use of the new technology. We estimate a reduced form of this model through the Heckman selection probit using a sample of plots545 distributed in the five regions of Togo. The estimation procedure is developed in two steps. In the first step, we estimate the first four moments of the benefit distribution and in the second step, we incorporate these estimated moments into the model of technology adoption and climate risk perception. We find that risk plays a central role in farmers' decisions, first through the direct effect of its perception and second through sampling moments of the yield distribution in the adoption model.

These results have important policy implications. First, the adoption of new and improved seed technologies to reduce production cycle length and enhance resistance to water stress can be used as a means of managing climate risk. Second, when a policymaker is considering the introduction of economic instruments (e.g., subsidies) to incentivize the adoption of innovative technologies, he or she should incorporate into the relevant cost-benefit analysis the expected benefits that farmers derive from the reduction in their production risk caused by adoption. Ignoring these benefits could lead to welfare-enhancing policies that do not meet a cost-benefit test. Finally, when the effect of a new technology on future returns is uncertain, the provision of adoption-related information induces faster diffusion among farmers, reducing the quasi-option value of adoption.

\section{REFERENCES}

1) Antle, J. 1983. "Testing the Stochastic Structure of Production: A Flexible Moment-Based Approach." Journal of Business and Economic Statistics 1:192-201. --. 1987. "Econometric Estimation of Producers' Risk Attitudes." American Journal of Agricultural Economics 69:509-22.

2) Apata, T.G. (2010) "Effects of global climate change on Nigerian Agriculture: An empirical analysis", Paper presented at the 84th annual conference of Agricultural Economics Society held in Edinburgh, Scotland, p 345351.

3) Asfaw Solomon (2013), "Adaptation to Climate Change and Food Security: Micro-evidence from Malawi", Invited paper presented at the 4th International Conference of the African Association of Agricultural Economists, September 22-25, 2013, Hammamet, Tunisia.

4) Boris Odilon Kounagbe Lokonon et al, 2019 The potential impact of climate change on agriculture in West Africa: A bioeconomicmodeling approach, Climate

5) Change Economics, doi: 10.1142/S2010007819500155 Dinar, A., Hassan, R., Mendelsohn, R., and Benhin J. (eds). (2008), Climate Change and Agriculture in Africa: Impact Assessment and Adaptation Strategies, London: Earth Scan.

6) Egbendewe, A. Y. G., Lokonon, B. K., Naga, C. Atewamba, C. (2016), Impact of Climate Change on Agricultural Trade and Food Security in ECOWAS. United Nations University Institute for Natural Resources in Africa. UNU-INRA, $2016, \mathrm{p} 1$. 


\section{Perception of Climate Risks and Issues of Adoption of Resilient Technologies by Farmers in Togo}

7) Gbetibouo, G.A. (2009), "Understanding farmers' perceptions and adaptations to climate change and variability: The case of the Limpopo Basin, South Africa". Environment and Production Technology Division. IFPRI Discussion Paper 00849. 2009. Washington (DC) IFPRI, www.ifpri.org/sites/default/files/publications/ifpridp0084 9.pdf.

8) Gnanglè C.P., Glèlè Kakaï,R. Assogbadjo,A.E., Vodounou, S., Yabi,J. A. and Sokpon, N, (2011), Past climate trends, modeling, perceptions and local adaptations in Benin. Climatology, vol. 8 (2011).

9) Huffman, W.E., and S. Mercier. 1991. "Joint Adoption of Microcomputer Technologies: An Analysis of Farmers' Decision." Review of Economics and Statistics 73:541-46.

10) Kihlstrom, R.E. 1976. "Firm Demand for Information About Price and Technology." Journal of Political Economy 84:133541.

11) Kim, K., and J.P. Chavas. 2003. "Technological Change and Risk Management: An Application to the Economics of Corn Production." Agricultural Economics 29:125-42.

12) Kurukulasuriya, P. and Mendelsohn, R. (2006) "A Ricardian analysis of the impact of climate change on African crop land", Centre for Environmental Economics and Policy in Africa (CEEPA), Discussion Paper $n^{\circ} 8$, University of Pretoria, Pretoria, South Africa.

13) Maddison D, (2007), The perception and adaptation to climate change in Africa. Policy Research Working Paper WPS4308. Washington (DC): The World Bank, Development Research Group, Sustainable Rural and Urban Development Team; 2007. $\quad$ www-wds.worldbank.org/servlet/WDSContentServer/WDSP/IB /2007/08/06/000158349_ 20070806150940/Ren dered/PDF/wps4308.pdf.

14) Mustapha SB, Sanda AH, Shehu H. (2012), Farmers' perception of climate change in central agricultural zone of Borno State, Nigeria. Journal of Environment and Earth Science,2 (11): 21-27.

15) Rashid, H. and Nhemachena, C. (2008), "Determinants of African farmers' strategies foradapting to climate change: Multinomial choice analysis"; AfJARE 2(1), March 2008.River State-Nigeria", Journal of Sustainable Development; 7:2; 2014.

16) Yegbemey RN, Yabi JA, Aïhounton GB, Paraïso A, (2014), Simultaneous modeling of climate change perception and adaptation: the case of maize farmers in Northern Benin (West Africa). Cah Agric 23: 17787. doi: 10.1684/agr.2014.0697.

17) Yesuf, M., Di Falco, S. Deressa, T. Ringler, C. and Kohlin, G. (2008), "The Impact of Climate Change and Adaptation on Food Production in Low-Income Countries: Evidence from Nile Basin, Ethiopia", International Food Policy Research Institute (IFPRI), Discussion Paper, 00828.

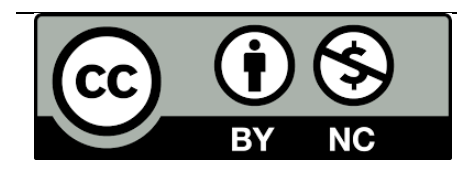

There is an Open Access article, distributed under the term of the Creative Commons Attribution - Non Commercial 4.0 International (CC BY-NC 4.0)

(https://creativecommons.org/licenses/by-nc/4.0/), which permits remixing, adapting and building upon the work for non-commercial use, provided the original work is properly cited. 